\title{
El derecho fundamental a la información para luchar contra la corrupción y controlar las fake news en Brasil
}

\author{
The fundamental right to information to fight \\ corruption and control fake news in Brazil
}

\author{
Isabela Moreira Domingos ${ }^{1}$ \\ connect.d@outlook.com \\ Pontifícia Universidade Católica do Paraná
}

\section{Resumen}

La presente investigación aborda los riesgos de las fake news y las "posverdades" para la democracia, esta cuestión sumada a la mala gestión y la corrupción frustra la protección de los derechos sociales fundamentales y crea un ambiente de inestabilidad institucional. Aunque la tecnología ayuda a la expansión de la comunicación y elimina las fronteras en el mundo globalizado, también implica en la reflexión sobre la "infodemia" y la monetización de las noticias falsas. La investigación por medio del enfoque analítico permite lograr un análisis sistemático del problema de las noticias falsas (fake news) durante la Covid-19, con el apoyo de la doctrina nacional y extranjera, así como el uso de artículos e informes sobre el tema.

\section{Palabras clave}

Desarrollo; Derechos Humanos; Información; Corrupción; Cumplimiento; Covid19; Brasil.

\begin{abstract}
Esta pesquisa aborda os riscos de notícias falsas e pós-verdades para a democracia, que, em conjunto com a má administração e a corrupção, minam a proteção dos

\footnotetext{
${ }^{1}$ Investigadora de la Universidad de São Paulo (USP/CEDMAR). Miembro del grupo Lepadia/UFRJ. Máster en Derecho Económico y Desarrollo por la Pontificia Universidad Católica de Paraná, con beca completa de la Coordinación para el Perfeccionamiento del Personal de la Enseñanza Superior (CAPES). Miembro de la Comisión y del grupo estudio de Compliance de la OAB (Colegio de Abogados de Brasil). Miembro del Grupo de Estudio de Derecho Electoral de la OAB (Colegio de Abogados de Brasil). Práctica docente en Derecho en la Pontificia Universidad Católica de Paraná. Postgrado en Estado Democrático de Derecho en la Fundación Escuela del Ministerio Público del Estado de Paraná (FEMPAR). Profesora universitaria internacional invitada para cursos de Derecho Digital (nivel de grado y postgrado). Escritora de libros sobre Compliance y autora de varios artículos publicados en revistas especializadas indexadas (nacionales e internacionales).
} 
direitos fundamentais sociais e criam um ambiente de instabilidade institucional. Enquanto a tecnologia ajuda a expansão da comunicação e elimina fronteiras no mundo globalizado, por outro lado, é necessário refletir sobre a infodemia e a monetização de notícias falsas. A pesquisa utiliza do método analítico permite uma abordagem sistemática do problema das fake news durante a Covid-19, com o apoio da doutrina nacional e estrangeira, assim como o uso de artigos e relatórios sobre o assunto.

\section{Keywords}

Desenvolvimento; Direitos Humanos; Informação; Corrupção; Compliance; Covid19; Brasil.

Recibido: $13 / 12 / 2021$

Aceptado: 27/12/2021

DOI: https://dx.doi.org/10.5557/IIMEI12-N23-001020

Descripción propuesta: Moreira Domingos, Isabela 2021. El derecho fundamental a la información para luchar contra la corrupción y controlar las fake news en Brasil. Métodos de Información, 12(23), 1-20

\section{Introducción}

La Declaración Universal de los Derechos Humanos (DUDH) de las Naciones Unidas de 1948 (UN, 1948) fue de gran importancia para la protección de los derechos humanos, ya que promovió su difusión y consolidó el sistema jurídico internacional para la protección de grupos en situación de vulnerabilidad socioeconómica, inmigrantes, refugiados de guerra, crisis políticas y ambientales.

La dignidad humana prevista en el artículo 1, apartado III, de la Constitución de la República Federativa de Brasil de 1988 es el fundamento del Estado Democrático de Derecho; sin embargo, Brasil está marcado por una amplia desigualdad social que se manifiesta descaradamente durante la pandemia de coronavirus. 
Los países con un bajo nivel de transparencia enfrentan déficits en la realización de los derechos sociales fundamentales, especialmente el derecho a la salud y el derecho a la educación. La corrupción implica la relación pública y privada, pero cuando alcanza forma sistémica, afecta no sólo a los negocios, sino también a la propia forma de ejecución de la Administración Pública y genera crisis institucionales.

En este escenario de conflicto, la corrupción afecta principalmente a las personas que necesitan el buen funcionamiento del Estado y la ejecución de políticas públicas para la materialización de los derechos sociales fundamentales. Durante la pandemia de Covid-19, se observa que las personas que no podían pagar un seguro de salud (hospital privado), así como las que no tenían el privilegio de trabajar en la modalidad de oficina en casa, tuvieron un impacto significativo en sus ingresos familiares, ya que se vieron severamente afectadas por el coste de prestaciones sanitarias y gastos relacionados con la Covid-19.

La ausencia de infraestructura influye en el bienestar de la población, además de los problemas históricos de corrupción y mala gestión en la salud pública, que comprometen la calidad en la prestación de los servicios públicos esenciales (DOMINGOS y GONÇALVES 2019).

Cabe destacar que las personas que viven en las periferias brasileñas enfrentan problemas históricos de acceso a los servicios públicos más básicos para la promoción de su dignidad, como son los servicios de recogida de basura, el transporte escolar, el suministro de energía y el saneamiento básico, entre otros. De acuerdo con la investigación realizada por el Instituto Brasileño de Geografía y Estadística (IBGE, 2019), la población de la región Norte consta de 18.430.980 habitantes, sin embargo, el $87,7 \%$ de la población no tiene recolección de aguas residuales, el ingreso de las personas sin saneamiento es de aproximadamente $\mathrm{R} \$ 593,21$ de $\mathrm{R} \$ 2.950,23$ mensuales (ingreso de las personas con saneamiento básico), mientras que 42.361 personas han sido hospitalizadas por enfermedades transmitidas por el agua, con base en datos del Sistema Único de Salud (SUS) de 2019. ${ }^{2}$

\footnotetext{
${ }^{2}$ La encuesta fue proporcionada por Painel Saneamento Brasil. Cf. TRATABRASIL $\quad$ ORG, 2019. Painel Saneamento [en línea]. Brasil: Trata Brasil Org. [Consulta: 03 octubre 2021]. Disponible en: < https://www.painelsaneamento.org.br/localidade?id=3>. Ver también: IBGE, 2019. Pesquisa Nacional por
} 
Con respecto a la región Nordeste, los datos muestran que hay 57.071.654 habitantes y la renta per cápita de las personas sin saneamiento es de 428,27 reales al mes, en contraste con la renta de las personas con saneamiento, que es de 2.500,60 reales al mes. Se puede observar que el $71 \%$ de la población sufre sin recogida de aguas residuales; esto dará lugar a 113.748 hospitalizaciones totales por enfermedades transmitidas por el agua. La región Centro-Oeste está formada por 16.297.074 habitantes, el 42,3\% no tiene recogida de aguas residuales, cuya renta es de 834,49 reales, lo que equivale a 6.758.551 personas. Según el informe, el ingreso de las personas con saneamiento en el Centro-Oeste es de R \$3.684,43. En 2019, hubo 27.738 personas hospitalizadas por enfermedades transmitidas por el agua en el Sistema Único de Salud (SUS). ${ }^{3}$

Según las mismas fuentes, la población de la región Sudeste está compuesta por 88.371.433 personas y, a pesar de una notable mejora en los índices de infraestructura, ya que el 79,5\% de la población cuenta con recogida de aguas residuales, hay un número significativo de personas que están al margen del mínimo existencial, alrededor de 17.973.827; de este modo, es evidente la desigualdad entre la población privilegiada y los que sufren la falta de políticas públicas de acceso al agua y alcantarillado, teniendo en cuenta que había 61.797 personas hospitalizadas por enfermedades transmitidas por el agua en el momento de la investigación en 2019.

Además de los problemas históricos de corrupción y mala gestión en la salud pública, durante la Covid-19, se han compartido burbujas de noticias falsas en todo el mundo. En consecuencia, las posverdades influyeron en la toma de decisiones, poniendo en riesgo la vida de los ciudadanos brasileños. Por lo tanto, existe una relación entre las fake news y la corrupción en la ofensa de los derechos humanos, creando asimetrías de información que afectan especialmente a las personas en situación de vulnerabilidad social y económica, además de constituir un obstáculo para el ejercicio de la democracia.

\footnotetext{
Amostra de Domicílios [en línea] Brasil: IBGE. [Consulta: 03 octubre 2021]. Disponible en: < https://biblioteca.ibge.gov.br/visualizacao/livros/liv101707 informativo.pdf $>$.

${ }^{3}$ IBGE 2019 y Cf. TrataBrasil.org 2019.
} 
El objetivo de esta investigación es analizar el impacto de las fake news y la corrupción en el acceso a la sanidad, en el sentido de que el entorno de desinformación crea un ambiente de posverdades, como los movimientos antivacunas y la automedicación, a menudo con el nexo causal de ofender a la democracia y favorecer a determinados lobbies con intereses egoístas. Se utiliza el método analítico, con el respaldo de la doctrina especializada y los informes sobre el tema.

\section{El impacto de la corrupción en la protección de los derechos sociales fundamentales}

La mala gestión y la corrupción en la Administración Pública sobrecargan la maquinaria estatal, que se vuelve incapaz de ofrecer servicios públicos de calidad a sus ciudadanos. Otra cuestión notable, sobre todo al analizar América Latina, es que la corrupción afecta a la forma de aplicar la ley, ya que para los individuos considerados "amigos", la ley se relaja, "se encuentra un camino", mientras que para los demás, el camino es largo y burocrático. Esta medida favorece sólo a una pequeña clase dominante y adinerada que dicta las reglas del juego de intereses.

En este escenario, la corrupción provoca una crisis institucional y deslegitima al propio Estado, hasta el punto de que se convierte en un problema transnacional y requiere la participación de diversos actores para superarlo, especialmente la población, que debe promover la transparencia pública a través de la democracia participativa y el control de los dirigentes.

El Banco Mundial (WORLD BANK, 1997) ya informó de que la corrupción se produce en esta relación comercial transfronteriza, por lo que es difícil para los Estados recopilar información sobre estas transacciones económicas debido al secreto de los datos, por ejemplo, la deep web. Además de la cooperación internacional, es importante invertir en el fortalecimiento de la legislación y los mecanismos de control.

El Estado realiza negocios que conllevan asociaciones público-privadas, compra productos de proveedores internacionales o contrata la prestación de servicios de multinacionales, lo que puede implicar diversos riesgos para el medio ambiente y la dignidad humana, como, por ejemplo, en el caso de 
desviación de propósito del interés público y la manipulación de licitaciones en áreas de preservación medio ambiente.

La Ley Anticorrupción brasileña (Ley n ${ }^{\circ}$ 12.846/2013) busca proteger a la Administración Pública nacional y extranjera, precisamente porque el legislador entendió la importancia de analizar los aspectos de la corrupción más allá de la frontera nacional. Dicha ley fue el resultado del trabajo preparado por la Convención de las Naciones Unidas contra la Corrupción (United Nations Convention against Corruption - UNCAC), adoptada por la Asamblea General de las Naciones Unidas en 2003, en la Conferencia de Mérida (México) (UNODC, 2003) y promulgada por Brasil mediante el Decreto $n^{\circ} 5.687 / 2006$.

La UNCAC busca restaurar la confianza en las instituciones, promoviendo la lucha contra la corrupción y sus múltiples efectos negativos en la sociedad, los mercados y los Estados. Por consiguiente, fomenta la cooperación internacional, respetando los principios de igualdad, soberanía y dignidad humana. Como se indica en los Objetivos de Desarrollo Sostenible (ODS) de la Agenda 2030 y en particular el ODS 17, la cooperación internacional puede ser a través de alianzas (UN, 2015a y 2015b).

Según Maria Sylvia Zanella Di Pietro (2021: 343), las Asociaciones PúblicoPrivadas (PPP, según su abreviación en portugués) fueron instituidas a través de la Ley 11.079/2004, ya que la hermenéutica constitucional reconocía sólo la concesión de servicio público, sin embargo, la interpretación actual promovida por la mencionada Ley de Asociaciones Público-Privadas admite la concesión en la modalidad patrocinada (servicio público que permite el cobro de tasas por servicios prestados) o administrativa. La nueva redacción dada por la Ley 14.133/2021, incluyó que la realización de negocios entre la Asociación Público-Privada debe ser precedida de licitación, ya sea en forma de concurso o diálogo competitivo, con base en los criterios establecidos por el art. 10 de la Ley 11.079/2004.

En este marco legislativo, se han publicado reiteradamente noticias que ponen el foco de atención en la corrupción en contratos que involucran a la Administración Pública y a empresas, que se aprovechan de la infraestructura del Estado brasileño para sobrevalorar productos y servicios. Aunque la Ley 
Nacional Anticorrupción prevé la responsabilidad legal en el ámbito civil y administrativo, en cambio, nada impide que los responsables sean procesados en el ámbito penal en la medida de su culpabilidad, respetando el principio de defensa contradictoria y amplia, previsto en el artículo $5^{\circ}$, inciso LV de la Constitución de la República de 1988.

João Ernesto Christófolo (2019: 579-580) considera que el deber de cooperación para el desarrollo internacional debe observar la capacidad real y los compromisos asumidos por cada Estado, con el objetivo de promover mejores condiciones de vida, la reducción de los déficits sociales, económicos, educativos y el respeto a los derechos humanos, tal como se prevé en el art. 13 de la Carta de las Naciones Unidas de 1945 (UN, 1945).

En los lugares donde prevalece el poder del crimen organizado, es posible identificar la injerencia de la Administración Pública en la corrupción de contratos que afectan a la prestación de servicios públicos y a la calidad del medio ambiente. Esto se traduce en una corrupción sistémica que erosiona las relaciones públicas y privadas, corrupción que se ve impulsada por la imposición de impuestos ilícitos, la violencia, la crisis económica y sanitaria en América Latina. Paulo Bonavides (2011: 380) entiende que las sociedades con economías debilitadas se insertan en una dinámica de inestabilidades que afectan el ejercicio de la democracia.

Durante pandemia de la Covid-19, se ha demostrado en primer lugar, el impacto que la corrupción tiene en la protección de los derechos humanos, exponiendo las vulnerabilidades socioeconómicas ya existentes en la sociedad, especialmente en la desigualdad en el acceso a la salud. En segundo lugar, ha quedado clara la necesidad de que los Estados miembros de la Convención de las Naciones Unidas contra la Corrupción trabajen de forma más proactiva en la prevención y represión de la corrupción transnacional, debido no sólo al impacto socioeconómico, sino también a la preservación de los derechos sociales fundamentales, como el acceso a los programas de asistencia social, dirigidos a las personas que realmente necesitan las prestaciones (p. ej., ayuda alimentaria), así como el control de los contratos para la mejor atención de los servicios públicos. Se observa que, en el entorno de la crisis, el sector de la contratación pública tiene un alto riesgo de fraude y sobrefacturación. 
Otro punto para el desarrollo de las naciones es la importancia de la participación ciudadana en las decisiones públicas, supervisando a los funcionarios electos a través de la democracia participativa y exigiendo la rendición de cuentas. Según la Convención de las Naciones Unidas contra la Corrupción (UNCAC), la participación de la sociedad refleja los principios del Estado de Derecho: integridad, responsabilidad, transparencia, legalidad, seguridad jurídica, división de poderes y justicia social, entre otros (UNODC, 2003).

En un buen gobierno, la democracia desempeña un papel importante, así como el equilibrio entre los tres poderes: Ejecutivo, Legislativo y Judicial. Si falta el equilibrio, quienes tienen el poder quedan expuestos a la tentación de abusar de él, en detrimento del interés público y la dignidad humana. El abuso de poder se traduce en la posibilidad de contener y manipular la información. Así, para Paulo Bonavides (2011: 552), la Constitución prevé en su artículo 5, el derecho de acceso a la información (XIX y XXXIII), haciendo sólida la protección contra los abusos de los organismos públicos, mientras que la separación de poderes se mueve a favor de la realización de los derechos fundamentales; por lo tanto, no se trata de la mera distribución de competencias.

\section{Corrupción y fake news en la sanidad pública durante la Covid-19 en Brasil}

El derecho a la salud es un derecho humano reconocido por la Organización de las Naciones Unidas (ONU) en la Declaración Universal de los Derechos Humanos (DUDH), pues entiende el derecho a la salud como un bien universal, en el sentido de que toda persona y su familia deben tener acceso a la salud para su bienestar, y es deber del Estado proporcionar asistencia a quienes no tienen medios de mantenerse; personas con alguna discapacidad, desempleadas, enfermas, ancianas, es decir, en la condición de vulnerabilidad o hiposuficiencia.

Para la consecución de la democracia constitucional es necesaria la participación de todos, especialmente de las minorías, y la garantía de la transparencia para el fundamento del Estado de Derecho democrático. La corrupción rompe la idea de lo que un Estado constitucional quiere conseguir: 
el bienestar; el desarrollo sostenible; la participación ciudadana; y el interés público.

Como ya se ha dicho, las posverdades pretenden despertar lo emocional e ignoran lo racional, es decir, los hechos objetivos, a menudo ya probados por la ciencia. El peligro radica en la industria del imaginario, ya que, como señala Eugênio Bucci (2018), una vez difundida en la esfera pública, la información escapa al control de los órganos de persecución, especialmente cuando las fake news se propagan en los motores de búsqueda y en las aplicaciones de mensajería instantánea (e.g., Whatsapp), llegando a las masas, lo que repercute en el poder de decisión de las personas vulnerables.

En esta hipótesis, desde el momento de la ocultación y no comparte los datos y destinos de los recursos públicos, frustra la experiencia del derecho a la información, ofendiendo todo el proceso histórico de realización de los derechos humanos y la democracia participativa. En respuesta, la rendición de cuentas permite conocer el destino real de los recursos públicos que son financiados por los contribuyentes, es decir, el pueblo, y, por lo tanto, permite identificar posibles sospechas de corrupción.

Como hemos visto, los observatorios sociales, el Ministerio Público y los Ministerios de Cuentas Públicas estatales y federales actúan en colaboración con el Congreso Nacional para fiscalizar al Estado brasileño en diversas esferas. En este sentido, cabe destacar que el Ministerio Público de Bahía en colaboración con el Centro de Combate al Cibercrimen (NUCCIBER), con el fin de promover la modernización administrativa y la seguridad institucional, implementó un canal de denuncias para combatir las fake news (MPBA, 2021). Además del ambiente de inseguridad informativa, la corrupción en la salud tiene como consecuencia la prestación de servicios públicos fuera de los estándares aceptables por los organismos técnicos nacionales y que también van en contra de las recomendaciones de la Organización Mundial de la Salud (OMS). De ahí la importancia de la inversión en la investigación, la tecnología e la innovación para que las universidades y centros técnicos de investigación creen autonomía para la producción de vacunas y estudios científicos, hecho que ha mostrado extrema relevancia durante la crisis de los coronavirus en el mundo, especialmente en los países en desarrollo con gran extensión territorial, como India (BBC, 2021) y Brasil. 
Dentro de este orden de ideas, las empresas malintencionadas y los políticos involucrados en esquemas fraudulentos aprovechan las lagunas legales en tiempos de crisis para sobrevalorar los productos y servicios. Se ha aludido a que durante la pandemia de Covid-19, se permitió la renuncia a la necesidad de una licitación para garantizar la compra urgente de respiradores y suministros sanitarios -la dispensa de las licitaciones pretende realizar los derechos fundamentales inmediatos de la población-, sin embargo, la corrupción en la Administración Pública se deja sentir en muchos países, no sólo en América Latina, pero cuando se trata de recursos para la salud y la lucha contra la Covid-19, provoca mucha indignación en la comunidad nacional e internacional.

En este sentido, es necesario mejorar el control de las cuentas públicas para proteger los derechos de la minoría vulnerable, que necesita los servicios públicos para hacer realidad los derechos sociales fundamentales, especialmente el acceso a la educación y la sanidad. La corrupción anula los derechos de las minorías para favorecer a una élite política dominante que actúa en su propio beneficio.

El acceso a la justicia exige un sistema judicial autónomo, lo que constituye una concepción del Estado moderno y democrático inclusivo. Este derecho no sólo es fundamental, sino un derecho humano previsto en el artículo 10 de la Declaración Universal de los Derechos Humanos de 1948. Así, las reformas legislativas deben ser para consolidar los derechos y no para retroceder y eliminar el equilibrio entre los tres poderes, en la misma línea de la Constitución de la República Federativa de Brasil (CRFB/1988).

En tal sentido, el derecho de acceso a la información y el derecho de acceso a la justicia son herramientas indispensables para neutralizar la arbitrariedad de los gobernantes y eliminar las asimetrías (de educación, información y consentimiento, entre otros), esas discrepancias que a veces pueden representar intereses oscuros para manipular y dirigir a la población. Frente a dichos intereses, el acceso a la información es el que posibilita analizar, impugnar y luchar contra los datos poco fiables. 
Desde este punto de vista, es necesario que la población tenga una base educativa para poder interpretar los datos e identificar si hay veracidad o información fraudulenta, sin embargo, es un proceso cognitivo complejo, por lo que es necesario implementar fuentes confiables para la publicación de noticias validadas, además de denunciar los contenidos con fake news.

En efecto, no se niega que las Tecnologías de la Información y la Comunicación (TIC) son un factor esencial para la globalización y la eliminación de fronteras en el acceso a la información. Pero, así como el cambio climático es un riesgo derivado de la modernidad, es importante destacar los riesgos del uso de la tecnología de la comunicación frente a la democracia: riesgos como el fenómeno de las fake news o la invasión de sitios web gubernamentales. Estos ciberdelitos afectan no sólo a las empresas, sino a las instituciones gubernamentales y no gubernamentales, así como a los ciudadanos, y la posibilidad del anonimato para la proliferación del odio en las redes sociales. Todos estos puntos deben ser debatidos en el espacio público, con el objetivo de crear soluciones más eficaces para la protección de la democracia-, en el sentido de que la información publicada no esté cargada de estereotipos dañinos y posverdades.

Luciano Meneguetti (2020: 15-69) considera que el término posverdad sigue aportando ambigüedad, porque es un fenómeno complejo, que está relacionado con la indiferencia de la cultura del otro. Este discurso está lleno de sesgos, con emoción, inclinación y conspiración, que crean obstáculos para que la gente busque la verdad. Esta información se difunde en Internet para la producción de fake news, ya que crea un clima de desinformación social en detrimento de la democracia.

Hanna Arendt (1977: 103-108) afirma en su texto "Derechos públicos e intereses privados", que la igualdad es una igualación de las diferencias. Para la autora, la consecución del bien común requiere de sacrificios de intereses personales para poder disfrutar de la felicidad pública, por lo tanto, se refiere a una crítica de cómo exigir la noción de idealismo a las personas económicamente desfavorecidas, sin que antes ejerzan efectivamente su papel de ciudadanos. Con este fin, el gobierno, las empresas y la sociedad civil deben proporcionar herramientas reales para que las personas puedan disfrutar de la esfera pública. 
En este pasaje sobre el derecho a la educación y a la información, por analogía, es necesario mencionar el fenómeno de las fake news. Entonces, ¿Cómo imponer a los ciudadanos el compromiso de control y mejor diligencia sobre la información compartida sin una educación pública de calidad? Como es bien sabido, Brasil tiene una amplia desigualdad social, especialmente en el acceso a la educación básica, un viejo problema que se ha agravado en un momento de aislamiento social forzado y la educación virtual (MARI, 2020; EBC, 2020), ya que una parte significativa de la población no tiene acceso a Internet.

La exclusión social en la pandemia es un reflejo de los problemas infraestructurales, políticos y socioeconómicos de Brasil. La población de la periferia, las zonas rurales y los afrodescendientes están entre los más excluidos digitalmente durante la pandemia (GRAGNANI, 2020).

La falta de conectividad dificulta el enfrentamiento a la crisis, la investigación de la Encuesta Nacional Continua por Muestreo de Hogares - Tecnologías de la Información y la Comunicación - PNAD (EBC, 2020) identificó que para el $4,5 \%$ de las personas que no tienen acceso a Internet, es porque el servicio no está disponible en su localidad. Ya según la edición de la encuesta TIC Domicilios $\mathrm{Br}$, el 35\% de los hogares de la región nordeste brasileña no tienen acceso a Internet; en cambio, el 95\% de la población más rica tiene algún tipo de dispositivo electrónico para conectarse. El número se reduce a menos de la mitad cuando se trata de la clase C (44\%) y llega a sólo el 14\% en las clases D y E. Por lo tanto, se puede ver que el uso de la red está vinculado a la condición socioeconómica, lo que representa una desigualdad digital entre los brasileños (MARI, 2020). De hecho, sólo con la reducción de la asimetría en la educación pública y el acceso a la red, la minoría tendría las herramientas para filtrar la información como correcta o incorrecta.

En las enseñanzas de Cortella (2020), en la era de la posverdad, el receptor tiene una creencia de lo que supuestamente es cierto, aunque la información no se corresponda con la realidad misma. Esto no significa que la persona tenga una mala intención en su divulgación, a diferencia de las fake news, en las que, quienes las generan tienen el interés en distorsionar la realidad o fabricar mentiras, favoreciendo a la industria de la desinformación que alimenta al 
periodismo sensacionalista, a las redes sociales y aplicaciones de mensajería, y a las organizaciones criminales que se benefician económicamente de la asimetría de la información.

José Marichal (2016: 19-22) señala la preocupación de los investigadores por el exceso de información que se expone en la web, en el sentido de que, en lugar de ampliar nuestra capacidad de cognición y reflexión, la banalidad y la acumulación de contenidos crea comodidad, en particular, su flujo constante afecta a la capacidad humana de retención y aprendizaje. El autor cita la avalancha de publicaciones en Twitter que mantienen a los usuarios siempre conectados y ocupados, sin embargo, este colectivo muchas veces no traduce el contenido real de la información; un proceso elemental para el ejercicio de una visión crítica y democrática del mundo.

De hecho, la burbuja informativa en el mundo virtual se debe a que los algoritmos promueven la formación de "redes homogéneas", es decir, la divulgación de información que podría ser el contrapunto del debate, no se ve y mucho menos se comparte. Como D. Scales, J. Gorman y K.H. Jamieson (2021) han estudiado en el contexto actual de la pandemia de Covid-19, la infodemia contribuye a un entorno nocivo de posverdades y fake news, favoreciendo a grupos políticos malintencionados y a los grandes lobbies que no cumplen con las directrices de transparencia.

\section{El acceso a la información como derecho de la ciudadanía}

La Constitución de la República Federativa de Brasil de 1988 (CRFB) considera el acceso a la información a todos y salvaguarda el secreto de la fuente, cuando es necesario para el ejercicio profesional. El derecho a la información es un derecho fundamental previsto en el artículo $5^{\circ}$, inciso XIV. Asimismo, la Ley de Acceso a la Información Pública (Ley 12.527/2011) busca fortalecer a los ciudadanos a través de una mayor libertad de expresión y opinión (PLANALTO, 2011). El Estado tiene el deber de promover la transparencia pública a través de portales adecuados, con lenguaje apropiado y de fácil conducción y comprensión, según lo previsto en el artículo 5 de la CRFB/1998. 
Tanto el acceso a la información como el ejercicio de la libertad de prensa son esenciales para la construcción de la ciudadanía. La prensa debe respetar los límites éticos, dada la función social de su actividad y el interés público.

La Declaración Universal de los Derechos Humanos de 1948 destaca la preocupación con la desigualdad en el acceso a la información, que no debe estar limitada por las fronteras, en la medida en que las minorías, como la población indígena, las mujeres afrodescendientes, las comunidades cimarrones, los representantes de las comunidades de la periferia, los ribereños, los ancianos, entre otros grupos que están subrepresentados en el poder político y en los puestos de liderazgo, claramente también acaban siendo desatendidos por los medios de comunicación y la conexión de banda ancha (wi-fi) ${ }^{(E B C, 2020)}$, que atiende preferentemente a los barrios con mejor infraestructura.

Los blogs, según Santos (2010) contribuyen a la difusión de la información ya que permiten el trabajo colaborativo en el entorno digital a través de la compartición de contenidos para la construcción del conocimiento y la deliberación democrática. Correia (2010: 72-88) identifica ciertas patologías en el periodismo tradicional, dada la asfixia de los espacios de deliberación de los grupos minoritarios, lo que impide la construcción de un espacio público ciudadano, es decir, pluralista, representativo e integrador, basado en la responsabilidad social del periodismo y de los medios de comunicación en compliance con el ordenamiento jurídico vigente. Este apoyo al bien común es el eje central del periodismo cívico. El autor también señala el riesgo del lenguaje estereotipado de las identidades, generalmente presente en los formatos mediáticos "infomerciales" persuasivos y predictivos que no tienen una preocupación real por la agenda pública de las minorías.

La democracia deliberativa permite a los ciudadanos justificar sus agendas y tener una discusión racional sobre los bienes jurídicos en cuestión (CORREIA, J. C., 2010: 76). Los Estados (lato sensu) deben promover espacios informales e institucionales de debate cívico para garantizar la participación de las poblaciones marginadas y vulnerables en los espacios públicos, es decir, crear herramientas de concienciación sobre la participación y la inclusión en la democracia, así como la importancia de la responsabilidad de los gobernantes, la rendición de cuentas, transparencia en la gestión de la salud y la evaluación 
de las políticas públicas. Estos aspectos se contemplan también en los ODS de la Agenda 2030 (UN, 2015a).

\section{Responsabilidad legal por las noticias falsas (fake news)}

En Brasil existen proyectos de ley que están siendo analizados por el Congreso Nacional para combatir las fake news, como el Proyecto de Ley $\mathrm{n}^{\circ}$ 2630/2020, que aborda el asunto de la desinformación (MPF, 2020a). En esta línea, hay expertos que defienden el establecimiento de plazos legales para que las plataformas retiren los contenidos ilegales ${ }^{4}$, de manera que los usuarios no tengan que recurrir directamente al Poder Judicial. Además, el Ministerio Público Federal ha elaborado una Nota Técnica sobre la cuestión de los proveedores de Internet. $^{5}$

El debate sobre las fake news implica los riesgos de la desinformación para la sociedad desde la perspectiva del principio de la dignidad humana. Aunque el ordenamiento jurídico brasileño no tipifica un delito específico para las fake newss, el Código Penal brasileño prevé tres delitos contra la dignidad y el honor: a) calumnia (imputación de un hecho falso, tipificado como delito en el artículo 138, castigada con detención, de seis meses a dos años, y multa); b) injuria (ofensa a la dignidad o al decoro, artículo 140, castigada con detención, de uno a seis meses, o el pago de una multa) y, c) la difamación (artículo 139, castigada con detención, de tres meses a un año, o el pago de una multa). ${ }^{6}$

En este sentido, las fake news pueden ser utilizadas como medio para cometer estos delitos. La responsabilidad legal no sólo recae en el político, funcionario o empresario, sino también en el ciudadano. Todos tienen el deber de verificar la información para detener la difusión de contenidos que pueden socavar la democracia y poner en peligro la salud y la dignidad de las personas.

Esta responsabilidad también debe recaer en los medios de comunicación, ya sean tradicionales o de masas, con base en el ordenamiento jurídico vigente.

\footnotetext{
${ }^{4}$ BRASIL. Câmara dos Deputados, 2021.

${ }^{5}$ Para más detalles: MPF, 2020a; 2020b.

${ }^{6}$ PLANALTO, 1940, Código Penal Brasileño de 1940. Decreto-Lei no 2.848 de 7 de dezembro de 1940. [en linea]. Brasil: Planalto. [Consulta: 03 octubre 2021]. Disponible en. <http://www.planalto.gov.br/ccivil_03/Decretolei/Del2848compilado.htm>.
} 
La Constitución de la República Federativa de Brasil de 1988 permite la libertad de expresión y prohíbe el anonimato, según el artículo 5, inciso IV (CRFB/1988). El legislador limitó el derecho a la libertad de pensamiento para proteger la dignidad humana contra los excesos. Se puede ver que detrás de las fake news, existe el interés de utilizarlas como masa de maniobra para fines oscuros con gran potencial económico y político.

Ya Aristóteles (2017: 2) advertía formas de degeneración del Estado, especialmente la tiranía, en la que el gobernante mira por sus propios intereses, amplificando la miseria y la desigualdad. Además, los servidores públicos deben rendir cuentas por las actividades realizadas y el salario, a fin de facilitar la transparencia. No obstante, esto no se contrapone con la Ley General de Protección de Datos Personales (LGPD No. 13.1709/2018, basada en el interés público (PLANALTO, 2018).

En el ordenamiento jurídico brasileño, el concepto de funcionario o servidor público se caracteriza por el individuo que ocupa un cargo, empleo, servicio o función pública (artículo 327 del Código Penal brasileño). Además, también se consideran servidores públicos quienes ocupan un cargo, empleo o función en una entidad estatal, o quienes trabajan para una empresa que presta servicios en el marco de un contrato o convenio, ejerciendo actividades propias de la Administración Pública, según el párrafo 1 de la citada disposición legal. ${ }^{7}$

El acceso a la información pública es un derecho fundamental en virtud del cual cualquier persona física, jurídica, nacional o extranjera, puede solicitar y recibir información de las instituciones de la Administración Pública. La Ley de Acceso a la Información (Ley n $\left.{ }^{\circ} 12.527 / 2011\right)^{8}$ tiene el alcance de facilitar el acceso y la democracia cívica, debido al principio de máxima publicidad, a favor de la transparencia en la actuación del Poder Público.

La información debe estar disponible en los portales de transparencia y necesita integrarse de forma equitativa sin discriminación de ningún tipo. Los procedimientos y formularios de solicitud de información, especialmente en

\footnotetext{
${ }^{7}$ La Ley número 8.027/1990 dispone sobre las normas de conducta de los funcionarios públicos de la Unión, Autarquías y Fundaciones Públicas, y otras disposiciones. Cf. PLANALTO, 1990; PLANALTO, 1940, Código Penal Brasileño de 1940.

${ }^{8}$ PLANALTO, 2011.
} 
los organismos públicos, han de estar disponibles de forma sencilla y accesible, sin que existan barreras ni dificultades para solicitarla. Como norma, la información solicitada debe ser gratuita para no obstaculizar el acceso a los más necesitados.

\section{Consideraciones finales}

El entorno de las posverdades y las fake news puede llevar a los individuos a errores sistemáticos en la toma de decisiones, que escapan a la racionalidad y al proceso de cautela en la búsqueda de fuentes oficiales y fiables. Es innegable el avance y la facilidad de acceso a la información a través de las redes sociales como Whatsapp, Facebook o Twitter, entre otras, lo que ha eliminado las barreras de comunicación e información, simplificando el acceso al simple "toque/tacto" en aplicaciones móviles, para descargar y compartir contenidos; por otro lado, el clickbait ha facilitado la difusión de noticias falsas por parte de grupos malintencionados con el fin de dirigir a las masas.

Es necesario reflexionar sobre el significado real y alcance de las tecnologías, sobre todo, para salvaguardar el derecho fundamental de acceso a la información, que es un paso imprescindible para la consecución de otros derechos, ya que interfiere directamente en la toma de decisiones para la elección de los políticos y en la evaluación de las políticas públicas.

Brasil ya experimenta los reflejos de los impactos negativos del juego de las posverdades, debido a los movimientos antivacunas, que influyeron en una parte de los adultos no vacunados y en el regreso de las enfermedades erradicadas, o la idea de la "tierra plana", entre otros. El uso de la tecnología de la información no debe contribuir a la regresión social, sino promover la responsabilidad social en el periodismo y los medios de comunicación tradicionales. También plantea desafíos y debe promover los medios eficaces para la prevención de fenómenos como las fake news y ayudar a esclarecer la responsabilidad legal de los responsables, teniendo en cuenta que la desigualdad social es un factor que contribuye a las asimetrías en el acceso a la información. 


\section{Bibliografia}

ARENDT, H., 1977. Public Rights and Private Interests: In Response to Charles Frankel. En: Mooney M, Stuber F (ed.), Small Comforts for Hard Times: Humanists on Public Policy. New York Chichester, West Sussex: Columbia University Press; 1977. p.103-108. Disponible en: https://doi.org/10.7312/moon92826-011

ARISTÓTELES, 2017. Ética a Nicômaco. Tradução de Antônio de Castro Caeiro. 2 ed. São Paulo: Forense. ISBN 978-85-309-7745-0

GRAGNANI, Juliana, 2020. Por que o coronavirus mata mais as pessoas negras e pobres no Brasil e no mundo? [en línea]. Brasil: BBC, 12 julio 2020. [Consulta: 03 out. 2021]. Disponible en: <https:/_www.bbc.com/portuguese/brasil-53338421>.

BBC, 2021. Vacina para covid: India aprova dois imunizantes e planeja vacinar 300 milhões de pessoas em 2021 [en línea]. Brasil: BBC 3 enero 2021. [Consulta: 03 out. 2021]. Disponible en: < https:/_www.terra.com.br/noticias/mundo/vacina-paracovid-india-aprova-dois-imunizantes-e-planeja-vacinar-300-milhoes-depessoas-em- 2021,b2aa3931e83ce58c758ccd6ce11dfba2b6mg0pqw.html>.

BONAVIDES, Paulo, 2011. Curso de Direito Constitucional. 26 ed. São Paulo: Malheiros. ISBN 978-853-920-065-8

BRASIL. CÂMARA DOS DEPUTADOS, 2021. Relator do projeto das fake news quer incluir proposta do governo em seu parecer [en línea]. Brasil: Câmara dos Deputados. [Consulta: 03 octubre 2021]. Disponible en: <https:/ /www.camara.leg.br/noticias/808359-relator-do-projeto-das-fakenews-quer-incluir-proposta-do-governo-em-seu-parecer $/>$.

BUCCI, E., 2018. Pós-política y corrosión de la verdad [en línea]. Revista USP, 116, 19-30. [Consulta: 03 octubre 2021] Disponible en: < https:/ /www.revistas.usp.br/revusp/article/view/146574/140220>. doi.org/10.11606/issn.2316-9036.v0i116p19-30.

CHRISTÓFOLO, J. E., 2019. Princípios constitucionais de relações internacionais: significado, alcance e aplicação. Belo Horizonte: Del Rey. ISBN 978-853-840-532-0

CORREIA, J. C., 2010. Novos jornalismos e vida cívica: limites e possibilidades do «jornalismo deliberativo». En: MORGADO, Isabel Salema; ROSAS, Antônio. Cidadania Digital. Covilhã: LabCom Books, p. 71-100. ISBN 978-989-654-0517

CORTELLA, Mario Sergio, 2020. O que é pós-verdade?. Brasil: Youtube; Canal do Cortella. [Consulta: 03 octubre 2021]. Disponible en: $\leq(40)$ O que é pósverdade? - Mario Sergio Cortella - You'Tube>.

DI PIETRO, M. S. Z., 2021. Direito Administrativo. 34 ed. Río de Janeiro: Forense. ISBN 978-853-099-333-7

DOMINGOS, Isabela Moreira y GONÇALVES, Ruben Miranda. 2019. População ribeirinha no Amazonas e a desigualdade no acesso à saúde. Revista de Estudos Constitucionais, Hermenêutica e Teoria do Direito (RECHTD), 11(1):99-108, eneroabril 2019, Unisinos - doi: 10.4013/rechtd.2019.111.06 . 
EBC, 2020. Um em cada 4 brasileiros não tem acesso à internet, mostra pesquisa [en línea]. Brasil: EBC. [Consulta: 03 octubre 2021]. Disponible en: < https://agenciabrasil.ebc.com.br/economia/noticia/2020-04/um-em-cadaquatro-brasileiros-nao-tem-acesso-internet $>$.

IBGE, 2019. Pesquisa Nacional por Amostra de Domicílios [en línea]. Brasil: IBGE. [Consulta: 03 octubre 2021]. Disponible en: < https://biblioteca.ibge.gov.br/visualizacao/livros/liv101707 informativo.pdf $>$.

MARI, Angelica, 2020. Negros e pobres sofrem com exclusão digital durante a pandemia [en línea]. Brasil: Forbes Tech, 27 mayo 2020. [Consulta: 05 octubre 2021]. Disponible en <https://forbes.com.br/forbes-tech/2020/05/negros-epobres-sofrem-com-exclusao-digital-durante-a-pandemia $/>$.

MARICHAL, J., 2016. Facebook democracy: the architecture of disclosure and the threat to public life. Routledge; Taylor and Francis Group; Kindle: Londres y Nueva York. p. 19- 22.

MENEGUETTI, L., 2020. Verdade, pós-verdade e fake news: aspectos conceituais e implicações. En: MENEGUETTI, L.; NOVAES, P.; L. P. y FREITAS, R. A. S. (Orgs.). Direitos humanos na era das fake-news e da pós-verdade. Birigui: Stábile.

MPBA, 2021. MP fortalece combate a fake news durante a pandemia do coronavirus [en línea]. Brasil: MPBA. [Consulta: 09 octubre 2021]. Disponible en: <https:/ /www.mpba.mp.br/noticia/55277>.

MPF, 2020a. Lei das Fake News: MPF propõe ao Senado mudanças em projeto de lei na pauta desde dia 25. Brasil: MPF. [Consulta: 09 octubre 2021]. Disponible en: $<\underline{\text { http: / / mpf.mp.br/pgr/noticias-pgr/lei-das-fake-news-mpf-propoe-ao- }}$ senado-mudancas-em-projeto-na-pauta-deste-dia-25 $>$.

MPF, 2020b. Nota Técnica $n^{\circ}$ 02/2020. Brasil: MPF. [Consulta: 09 octubre 2021]. Disponible en:

< http://www.mpf.mp.br/pgr/documentos/NotaTecnicaPL26302020provedoresdei nternet.pdf $>$.

PLANALTO, 1940, Código Penal Brasileño de 1940. Decreto-Lei $n^{\circ} 2.848$ de 7 de dezembro de 1940 [en línea]. Brasil: Planalto. [Consulta: 03 octubre 2021]. Disponible en: <http://www.planalto.gov.br/ccivil 03/Decretolei/Del2848compilado.htm $>$.

PLANALTO, 1990. Lei $n^{\circ} \quad 8.027 / 1990$ [en línea]. Brasil: Planalto. [Consulta: 03 octubre 2021]. Disponible en: $<$ http://www.planalto.gov.br/ccivil 03/LEIS/L8027.htm>.

PLANALTO, 2011. Lei de acesso a informação pública (LAI- Lei na 12.527/2011 [en línea]. Brasil: Planalto. [Consulta: 03 octubre 2021]. Disponible en: <https:/_www.planalto.gov.br/ccivil 03/ ato20112014/2011/lei/112527.htm>.

PLANALTO, 2013. Lei Anticorrupção. (Lei no 12.846/2013 de $1^{\circ}$ de agosto de 2013). Ley Anticorrupción brasileña. [en línea]. Brasil: Planalto. [Consulta: 03 octubre 2021]. 
Disponible en: $\quad$ http://www.planalto.gov.br/ccivil 03/ ato20112014/2013/lei/112846.htm

PLANALTO, 2018. Lei Geral de Proteção de Dados. (LGPD - Lei n 13.709/2018) [en línea]. Brasil: Planalto. [Consulta: 03 octubre 2021]. Disponible en:

< http://www.planalto.gov.br/ccivil 03/ ato2015-2018/2018/Lei/L13709.htm>.

SANTOS, R., 2010. Media Digitais e Responsabilidade Social En: MORGADO, Isabel Salema; ROSAS, Antônio. Cidadania Digital. Covilhã: LabCom Books, p. 59-70. ISBN 978-989-654-051-7

SCALES, D.; GORMAN, J. y K. JAMIESON, 2021. The Covid-19 Infodemic Applying the Epidemiologic Model to Counter Misinformation. The New England Journal of Medicine, 385(8):678-681. [Consulta: 10 octubre 2021]. Disponible en: <https:/ _www.nejm.org/doi/pdf/10.1056/NEJMp2103798?article'Tools=tru $\underline{\mathrm{e}}>$.

TRATABRASIL ORG, 2019. Painel Saneamento [en línea]. Brasil: Trata Brasil Org. [Consulta: 03 octubre 2021]. Disponible en:

$<$ https:/ /www.painelsaneamento.org.br/localidade?id=3>.

UN, 1945. Carta de las Naciones Unidas [en línea]. San Francisco: Naciones Unidas. [Consulta: 10 octubre 2021]. Disponible: < https://www.un.org/es/about-us/un-charter/full-text $>$.

UN, 1948. Declaración Universal de los Derechos Humanos [en línea]. San Francisco; Naciones Unidas. [Consulta: 10 octubre 2021]. Disponible en: https://www.un.org/es/about-us/universal-declaration-of-human-rights

UN, 2015a. Transforming our world: the 2030 Agenda for Sustainable Development. Brasil: ONU [en línea]. [Consulta: 10 octubre 2021]. Disponible en: $<\underline{\text { https://sdgs.un.org/2030agenda }>}$

UN, 2015b. Alianzas para lograr los objetivos. Fortalecer las bases de implementación y la revitalización de la alianza global para el desarrollo [en línea]. México: UN. [Consulta: 10 octubre 2021]. Disponible en: <https://mexico.un.org/es/sdgs/17>.

UNODC, 2003. Convenção das Nações Unidas contra a Corrup̧ção [en línea]. New York: UNODC. [Consulta: 10 octubre 2021]. Disponible en: < https:/_www.unodc.org/lpo-brazil/pt/corrupcao/convencao.html>.

WORLD BANK, 1997. Helping Countries Combat Corruption: The Role of the World Bank. [en línea]. Washington D. C.: WORLD BANK GROUP [Consulta: 10 octubre 2021]. Disponible en: <http://www1.worldbank.org/publicsector/anticorrupt/corruptn/cor08.htm $>$. 